\title{
Los días terrenales: la distorsión y la perversidad a partir de la vinculación ecfrasis-protagonistas
}

\author{
Gabriela Trejo Valencia \\ Universidad de Guanajuato
}

Resumen

El presente texto busca analizar la novela mexicana Los días terrenales, de José Revueltas, desde un enfoque ecfrástico que permite ampliar las semantizaciones y sentidos del relato. Propongo una lectura que (re)valore los elementos extratextuales (espacios otros, carteles, pinturas) presentes en la novela con el fin de dilucidar cómo los recursos ecfrásticos develan una distorsión análoga a la de los protagonistas. Así, se revisará que en Los días terrenales la obra de El Greco, un cuadro de Georges Braque y un afiche político poseen una gran densidad simbólica que apuntala la perversión implícita en toda la narración.

Palabras clave: ecfrasis, extratextual, distorsión, perversión, espacio.

\section{Abstract}

This text seeks to analyse the Mexican novel Los días terrenales by Jose Revueltas from an ekphrasis approach that allows to expand the meanings and senses of the story. I propose a reading that (re)assess the extra textual elements (spaces other, posters, paintings) presents in the novel in order to elucidate how ekphrasis resources unveil a distortion 
similar to the protagonists. Thus, it is devoted to the review that Los días terrenales the work of El Greco, a painting by Georges Braque and political poster have a high symbolic density that underpins the perversion implicit throughout narrative.

Keywords: Ekphrasis, Extra textual, Distortion, Perversion, Space.

Tosé Revueltas publica Los días terrenales en 1949, novela que habría de convertirse en piedra de toque en cuanto a la (re)visión y análisis teórico-crítico de su producción literaria. Lo anterior es comprensible si pensamos que desde su publicación la novela disgustó a la militancia comunista del país, ${ }^{1}$ ante todo porque sus personajes poco o nada favorecían a su concepción política; es más, "La visión de la mayor parte de los militantes deja de ser la suma de positividades — solidaridad, fraternidad, amanecer, luz, futuroque había sido en las dos novelas anteriores [Los muros de agua y El luto humano]" (Negrín, 1995: 211).

El que Los dias terrenales fuera una obra polémica y discutida (que incluso tuvo un carácter restringido durante sus primeros años) propició que se convirtiera en un texto clave dentro de la obra de Revueltas. Tan es así que la novela implica una multiplicidad de lecturas que la hacen partícipe de una amplia gama de dilucidaciones teóricas; un buen número de ellas se atienen precisamente a la relación del contenido del texto con el mundo extratextual $^{2}$ tocante a su autor, quien de hecho, fue miembro activo

${ }^{1}$ Figuras del marxismo y miembros del Partido Comunista vieron lesionados principios de su doctrina política con la novela del autor duranguense. Revueltas fue acusado de exhibir el lado oscuro del comunismo e inclusive fue presionado para sacar su libro del mercado. En consonancia con esta tendencia crítica, Revueltas llegó a tachar su novela como un libro "inconveniente, inadecuado y desmoralizador" para la causa (Revueltas, 2001, 26).

${ }^{2}$ Diferentes miradas críticas apuntan a la insoslayable relación de las novelas de Revueltas con su postura ideológica, la cual permea con fuerza en su pro- 
del Partido Comunista Mexicano hasta 1943, año en el que fue expulsado debido a su postura crítica.

Una vez puntualizado esto es preciso reiterar que es harto recurrente elucidar la obra de Revueltas con base en un referente extratextual. De ahí nuestro enfoque en una vertiente que pone en relación determinados elementos de la novela con referentes ajenos a la obra misma. Específicamente proponemos un análisis de carácter ecfrástico, el cual consiente la relación del espacio textual de Los días terrenales con un espacio externo. $Y$ es que aunque en la narrativa toda descripción apunta a una espacialidad significativa, cuando se describe un espacio otro existente fuera del texto pueden potenciarse las semantizaciones al establecerse vínculos extratextuales, "el espacio diegético, al interior del cual se establecen relaciones intra o intertextuales respecto de otros espacios del mundo real o del mundo ficcional" (Cuevas, 2006: 48). Es en estas relaciones donde buscamos puntualizar.

En el devenir del texto habremos de tratar la ecfrasis como la representación verbal de una representación visual, o en concreción, como el recurso que "designa el ejercicio literario de descripción de un objeto de arte" (Mesa, 2010: 173). ${ }^{3}$ Seamos puntuales, la ecfrasis presupone una especie de puente entre el espacio textual y el espacio extratextual que magnifica o sensibiliza al lector con ciertos sentidos y connotaciones. Partiendo de esta noción esclareceremos si las referencias a objetos plásticos y las descripciones de las espacialidades representadas en ellos se constituyen como claves

ducción. Dentro de esta perspectiva destacan investigadores y estudiosos como Andrea Revueltas, Evodio Escalante, Edith Negrín u Octavio Paz. Para éste último, por ejemplo, el cristianismo y el paradójico ateísmo marxista de Revueltas difícilmente pueden dejarse de lado cuando se analiza su obra.

${ }^{3}$ Con todo, la ecfrasis tiene una larga historia, originalmente se trataba de una descripción "extendida, detallada, vívida, que permitía presentar el objeto ante los ojos" (Pimentel, 2003: 205); es decir, la ecfrasis no remitía sólo a objetos artísticos como en la contemporaneidad. 
de lectura en la novela; todo ello bajo la luz de una problematización: ¿La ecfrasis permite subrayar la distorsión del hombre en Los días terrenales?

A primera vista podría cuestionarse el motivo de indagar en una temática abordada ya por importantes críticos revueltianos, entre quienes se afirma: "la novela se fundamenta en la carencia que todo lo deforma” (Escalante, 1999: 133); no obstante, abordaremos la deformación desde un vínculo diferente respecto al de las interpretaciones previas. ${ }^{4}$ De tal suerte, nuestra propuesta de lectura apunta a magnificar la distorsión y perversidad (perturbación al orden o estado natural $)^{5}$ de Gregorio, Julia y Fidel, sobre todo atendiendo a su relación con la ecfrasis.

Para lograr nuestro objetivo dilucidaremos la correspondencia entre Gregorio y la pintura de Doménicos Theotocópoulos (El Greco), entre Julia y el cartel ruso de propaganda, y finalmente veremos a Fidel ante el cuadro de Georges Braque. Analizaremos estos espacios otros como detonantes para la exposición de la distorsión que los personajes advierten a su alrededor. Aunado a ello, vislumbraremos que a partir de dicha reflexión el lector potencializa la perversión de cada uno de los protagonistas.

${ }^{4}$ Buena parte de la crítica se enfoca en la deformación generalizada de los personajes bajo la luz del fracaso del movimiento comunista. En este sentido, los personajes son partidarios comunistas deformados "puesto que el partido es irreal, sus militantes no pueden ser sino personajes fantasmáticos, grotescos, esto es, condenados a vivir en la sombría gruta de la irrealidad, deformados como lo están, por la carencia de su ser histórico" (Escalante, 1999: 130). Compartimos la idea de la deformación pero optamos por no revisarla sólo bajo esta perspectiva política, para ello orientamos nuestro acercamiento analítico a las referencias plásticas (pinturas, carteles) presentes en la novela.

${ }^{5}$ Entendemos el término pervertir en dicho sentido. Por tanto, es vital destacar que la palabra pervertir no debería connotarse aquí en su acepción sexual o moral de viciar con malas doctrinas o ejemplos. 


\section{Ecfrasis}

Conviene no olvidar en lo sucesivo que en literatura el recurso ecfrástico involucra la ilusión de estar ante un elemento visual. Como vemos, un carácter inherente de la ecfrasis es la ponderación de lo que se ha venido llamando una epistemología visual (Krieger, 2000: 146), la cual funciona como soporte y eje extratextual de la narración, pues como la ecfrasis parte de un referente proveniente de otras expresiones artísticas, entonces posibilita acudir a esas referencias otras y "desbordar" al texto.

Evaluamos que la ecfrasis forma parte vital del sistema discursivo y se constituye como factor para consolidar una lectura ${ }^{6}$ porque, parafraseando a Luz Aurora Pimentel, el objeto artístico como referente extratextual suele pasar a un primer plano para el sentido del texto. Siguiendo esta lógica, parecería que la ecfrasis superpone lo visual a lo literal y desdeña las diferencias entre un objeto visto y uno descrito, apuntando así a favorecer el célebre lema horaciano de "Ut pictura poesis". Sin embargo, la ecfrasis denota las diferencias entre representaciones verbales y visuales empezando porque: "A verbal representation cannot represent - that is, make present - its object in the same way a visual representation can. It may refer to an object, describe it, invoke it, but it can never bring its visual presence before us in the way pictures do. Words can «cite», but never «sight» their objects" (Mitchell, 1994: 152). A partir de esta divergencia sustancial entre el objeto artístico visto

${ }^{6}$ Es momento de advertir la existencia de tres clases de ecfrasis, como señala Luz Aurora Pimentel en su texto Ecfrasis y lecturas iconotextuales. Se trata de la llamada ecfrasis referencial: el objeto plástico tiene existencia material autónoma fuera del texto; ecfrasis nocional: el objeto representado existe en y por el lenguaje solamente; ecfrasis referencial genérica: no designa con precisión un objeto plástico, describe el estilo o la síntesis imaginaria de varios objetos plásticos de un creador. 
y el objeto artístico verbalizado, entendemos que cuando un texto literario refiere una obra plástica es porque ésta puede funcionar para complementar o potenciar el sentido textual. Entonces, la representación verbal de una representación visual cobrará singular importancia.

Tal importancia ecfrástica la vemos en Los días terrenales, donde está claro que un factor suplementario visual (con propiedades expresivas, formales y estilísticas diferentes a las del significante lingüístico lineal) puede ampliar las semantizaciones y sentidos de la novela. En suma, Los dias terrenales es uno de esos textos que "se comporta como si tuviera necesidad de un ejemplo [de índole visual] que trascendiera su propio discurso" (Riffaterre, 2000: 174). Estos ejemplos ecfrásticos tienen un significativo papel en la novela de Revueltas, basta pensar en su presencia en escenas claves, como cuando Gregorio se encuentra perdido y desorientado entre la miseria de los pescadores, Julia ha perdido a su hija, y Fidel bordea la sinrazón y el delirio de persecución en medio de la nada. Mediante el recurso ecfrástico, José Revueltas despliega reflexiones en sus personajes y en el propio lector, como comenzaremos a ver a continuación.

\section{Gregorio-Entierro del Conde de Orgaz ${ }^{7}$}

La primera mención a la pintura de El Greco se da cuando Gregorio encuentra similitudes entre la situación de los pescadores y la del cuadro del artista espańol. Gregorio es capaz de establecer dicha conexión visual gracias a que ha tenido una formación académica en San Carlos, por ende, posee cierto bagaje cultural y referencias claras de la historia del arte.

${ }^{7}$ La obra creada entre 1586 y 1588 pertenece al estilo manierista. 
Ahora bien, tanto en la escena de los pescadores veracruzanos como en la pintura, los cuerpos de los individuos representados están deformados; de hecho, en ambos contextos puede observarse que los hombres están "nocturnos y alargados, con el mismo impulso de sobrenatural crecimiento hacia lo más alto de la noche, hacia el imposible cielo. El mismo impulso de crecer" (Revueltas, 1979: 23). Justo entonces Gregorio recuerda las palabras de su maestro en la Academia: el evidente alargamiento de las figuras pictóricas de El Greco no se debía a su posible astigmatismo sino a una intencionalidad artística, "las figuras de El Greco se alargan hacia el cielo para representar la elevación del espíritu humano hacia Dios" (Revueltas, 1979: 23). ${ }^{8}$ En suma, pareciera que en ambas espacialidades hay una necesidad de salir de la condición terrena para alcanzar a Dios (dispuesto pictórica y jerárquicamente en un plano superior).

Gregorio comprende de golpe que así como se percibe con los personajes del cuadro, también los pescadores del Ozuluapan quieren alcanzar un paraíso prometido. El ser humano pasa su vida distorsionando su condición terrena para algún día disfrutar del cielo, por eso cree en promesas divinas y anda por el valle de lágrimas esperando sólo el momento de elevarse hacia Dios y dejar atrás el dolor: "todo rostro humano está deformado entonces, por verdades o por creencias particulares. De tal suerte, que cada quien se haya convertido en su propio monstruo, aunque no se dé cuenta de ello" (Escalante, 1999: 132). Citas como esa apuntan a que en la novela están presentes la enajenación religiosa y dogmática (como veremos en los apartados siguientes), así como el fanatismo, aspectos todos deformadores de la racionalidad. Basta pensar en

${ }^{8}$ Una intencionalidad artística que también encontramos en la novela, donde, como iremos explicando, la representación deformada de los protagonistas obedece a una concepción perversa del hombre, misma que puede verse reflejada en las diferentes ecfrasis. 
el significado de enajenar, el cual remite a sacar a alguien fuera de sí, es decir, perturbarlo, desviarlo, deformarlo; de tal modo, entendemos la idea de enajenación como una distorsión que puede apreciarse simbólicamente en la corporeidad de los personajes que pueblan Los dias terrenales.

Los pescadores del Ozuluapan son percibidos por Gregorio como individuos deformados no sólo física sino también psicológicamente. En efecto, Gregorio (quien ha llegado a Veracruz como asesor político) trata con hombres que pervierten la idea de una vida plena por atenerse a una serie de restricciones religiosas y sociales que los mantienen reducidos y controlados. Gregorio termina de ratificar esta percepción cuando presencia la aparente aproximación de los pescadores hacia Dios (por efecto del fuego de las hogueras). Ellos también parecen estirarse como en El entierro del Conde de Orgaz, "los tallos y los brazos aún más religiosamente finos desde su intencionado alargarse, desnudos como aquí en las orillas del Ozuluapan” (Revueltas, 1979: 22). A raíz de esta comparación Gregorio se percata de que así como "lo esencial en el Greco es la deformación” (Escalante, 1999: 131), lo esencial en su contexto es la misma distorsión física, pero también moral y psicológica. El recuerdo de su época como estudiante de arte se convierte en una reflexión que lo lleva a exaltar la distorsión humana en medio de esa existencia infeliz. La libertad o el progreso no tienen cabida entre los pescadores pues la pobreza y la religiosidad deforman sus vidas, y es imposible enderezar la dirección porque los caminos son por demás retorcidos.

Al salir de la novela para buscar la pintura notamos que las imágenes del rostro alargado apuntan a una significación importante dentro de la narración, en ella también la faz se presenta deformada. Esta distorsión es una caracterización trascendental en el texto pues es un símbolo de la animalización y de la perversión del orden armónico ordinario en el hombre: por eso Julia tiene 
apariencia de perro castigado, la facha de Fidel es de bestia insensible, el Tuerto Ventura representa a una criatura mitológica, los hombres tienen aspecto de mico y las mujeres parecen pajarracos. La distorsión física alcanza también a las extremidades superiores, esto último es significativo porque como se dice en la novela: "las manos distinguen al hombre, porque las manos son el trabajo y la creación y la fecundidad" (Revueltas, 1979: 27); pero en medio de la pobreza el hombre no se diferencia del animal, al contrario, por eso Bandera tiene sus manos tiesas como arańas, Ventura es manco y las manos de los ciegos están "crispándose en el aire igual que las frenéticas garras de medio centenar de aves de rapina, ansiosas de sujetarse a cualquier punto del espacio" (Revueltas, 1979: 229; cursivas mías). La insistencia de Revueltas en no describir manos ordinarias que apunten a individuos ordinarios parece consentir la idea de la distorsión en sus personajes: ${ }^{9}$ la deformación física es tal, que ciertos individuos prácticamente han perdido sus cualidades humanas: el Tuerto Ventura, el camarada Cabañas, Bandera o la enfermera son ejemplos paradigmáticos de la asimetría y la desproporción, están tan distorsionados que desequilibran la disposición natural de un cuerpo armónico.

El valor que le da Gregorio al cuadro de El Greco es una clave para el lector, "una instrucción de lectura, un modelo insertado dentro del texto para que a partir de él sepamos discernir cuál es la deformación específica de cada uno de los personajes" (Escalante, 1991: 213). Pero nuestra propuesta de lectura no se limita a esto, más bien señala que las ecfrasis están mediadas por tres personajes quienes perciben la distorsión a su alrededor pero no son capaces

${ }^{9}$ Gregorio, Fidel y Julia tienen manos normales en apariencia pero simbólicamente estos personajes no tienen extremidades superiores, la pobreza los ha pervertido, los ha discapacitado para ser felices. La miseria en la que viven los ha convertido en seres mancos y lisiados al negarles toda oportunidad para progresar. 
de advertir su propia perversión, por eso Gregorio admite su condición de mártir hasta el final de su historia, cuando se convierte en una especie de Cristo sacrificado.

Finalmente, las reflexiones desprendidas de El entierro del Conde de Orgaz nos llevan a concluir que en la distorsión característica de la obra, Revueltas ha encontrado una forma de soportar extraliterariamente su exposición de la deformación humana. La ecfrasis le permite recalcar la concepción del cuerpo en su novela como algo pervertido. Por ańadidura, el recurso ecfrástico funciona como una metáfora visual, la cual, al enmarcar la distorsión desarrolla una significación global. Por ende, las ecfrasis tienen una motivación en la novela, esto se dilucida en una confrontación entre el objeto descrito y el objeto visto, así se obtiene un efecto psíquico y estético para maximizar la comprensión del texto; es decir, la novela gana en significación al re-conocerse el objeto artístico.

Una vez puntualizado lo anterior, es preciso resaltar que en el texto la referencialidad a diversos objetos artísticos se acompańa de indicaciones explícitas a lugares como el río Ozuluapan o la ciudad. Tales referencias forman parte del estatuto de realidad del texto, pues a pesar de que no todos los lugares descritos en la novela tengan un referente extratextual real, están sostenidas en vértices lingüísticos, lógico-lingüísticos y narrativos suficientemente sólidos como para no tener que acudir al espacio extratextual. Sin embargo, cuando hay una descripción de un objeto plástico real como el cuadro de El Greco (ecfrasis referencial) es importante acudir al mismo para consolidar el despliegue de la mayor parte de los sentidos en el entramado de la novela.

Se sale del texto en el caso ecfrástico porque un objeto plástico es un discurso mediatizado por un autor, por eso se fija una intertextualidad. No olvidemos que existe una diferencia entre la designación literaria del espacio del río Ozuluapan (existente en Veracruz) y las imágenes referidas. El río no es un discurso pues no 
ha sido verbalizado previamente por otro creador y no hay forma de inferir una apelación a otra esfera discursiva en donde el río fuera un constructo inteligible y un espacio significante. El caso de la pintura es distinto, El Greco lo ha mediatizado artísticamente, de ahí que las descripciones de Revueltas de ese espacio visual lleven a realizar una lectura dimensional del referente, puesto que al ser un objeto artístico posee una discursividad que lo vuelve inteligible y no sólo sensible como el espacio del río. Gracias a la puesta en marcha de este proceso de intertextualidad es pertinente salir de la novela para el encuentro con el espacio significado discursivamente en el cuadro.

Lo anterior también atañe a las ecfrasis referenciales genéricas de la obra de Braque y el cartel propagandístico pero de forma distinta. Veamos, al no designar con precisión esos espacios otros, Revueltas parece advertir que para él el valor no está en una obra específica sino en el estilo o la síntesis del creador o de la época. Es cierto que el cuadro y el cartel son sólo representativos del movimiento cubista y los diseños soviéticos de difusión pero no por ello resultan menos significativos en la novela. Estas referencias están lejos de ser fortuitas y es viable atenderlas para extender su simbolización a la narración, y pese a no poder acudir al objeto plástico concreto, al menos conocer la vertiente a la que pertenecen, sobre todo para ubicarnos en el escenario artístico y contextual referido por Revueltas.

Detengámonos un momento aquí porque antes de continuar con las otras vinculaciones es necesario ahondar en la circularidad interpretativa de las ecfrasis en la novela. Interiorizar el referente da pie al proceso circular de la ecfrasis en donde el lector sale del texto para identificar el espacio extratextual pero vuelve a la diégesis pues ella ha construido otro espacio representado, uno que al desprenderse del real implica ciertas significaciones que cobrarán 
pleno sentido al relacionar texto y objeto. En este "ir y venir" se identifican dos momentos: identificación y construcción.

El momento de la identificación se da cuando el lector distingue la obra plástica representada. Para consolidar la identificación el lector debe fungir como intermediario, es decir, gracias a su enciclopedia cultural podrá o no identificar el recurso ecfrástico (específico o general). Pero más que eso deberá ser capaz de notar la identificación subjetiva del autor: ${ }^{10}$

Aun cuando la citación remita a un objeto plástico con nombre y apellido, el texto actuará como una especie de guía que orientará la percepción del objeto referido como tal. Aún en el momento de la identificación el lector tenderá a focalizar ese objeto referente sólo en los términos que le propone el objeto-texto; dejará incluso de ver partes del objeto plástico que no figuren en su representación ecfrástica (Pimentel, 2001: 115).

El otro momento es el de la construcción o el de la composición inédita del referente, porque aun cuando el texto cite un objeto ya identificado por el lector, cuando éste salga de Los días terrenales hacia el encuentro con esos espacios otros, los reconfigurará semánticamente: "resignificara ambos textos, el plástico y el ecfrástico sobre los detalles que el texto le ofrece" (Pimentel, 2003: 208). El lector vuelve al texto para darse cuenta de que las ecfrasis han influido en su recepción. De tal suerte, "si el impulso ecfrástico tiende, en un primer momento, a una relación analógica con el ob-

${ }^{10} \mathrm{Al}$ no hacer una ecfrasis crítica de análisis formal que se atiene a la descripción exacta del espacio representado en las obras, Revueltas engrandece o minimiza elementos de la espacialidad configurada en las ecfrasis según sus intereses. De ahí que no podamos exigirle al autor una descripción detallada que sea íntegra (porque no carece de ninguna de sus partes) y específica; es más adecuado enfocarnos en dilucidar el porqué de los detalles que sí ofrece, los cuales permiten leer una intencionalidad inherente o una semantización particular. 
jeto plástico [identificación], a la larga termina pareciéndose más a la red de significaciones del contexto verbal que al objeto que pretende representar [construcción]" (Pimentel, 2005: 205). Este proceso en donde el texto requiere al referente y éste necesita de la descripción textual para significar dentro de la diégesis, lleva a obtener sentidos que podrían haberse pasado por alto de no tomar en cuenta la relación de los protagonistas con las ecfrasis.

\section{Julia-cartel}

Siguiendo el camino ya trazado, señalamos que otra ponderación de la distorsión de un personaje en Los días terrenales se desata a partir de un antiguo cartel propagandístico de la revolución rusa. Éste se encuentra en una de las paredes de la oficina clandestina donde permanecen ocultos el líder comunista Fidel y su pareja sentimental, Julia. En tal afiche se observa la siguiente imagen:

Un grupo de trabajadores, tras una ametralladora Maxim, durante el asalto en 1917 al Palacio de Invierno [...] Era una imagen llena de energía y denuedo, que en cierto modo podría considerarse superior al trabajo del artista, cuya probable mediocridad, como sucede ante hechos muy vivos, poderosos y fecundos, se iluminaba como una especie de genio, proveniente, en primer lugar, del propio acontecimiento histórico (Revueltas, 1979: 65).

Esta ecfrasis referencial genérica funciona como un desencadenante para la situación narrativa, ${ }^{11}$, gracias a ella Julia comprende de golpe la enorme distorsión y perversión que la rodea y sobre todo, la sobrepasa. Basta pensar que el recurso ecfrástico se inserta justo

${ }^{11}$ Aunado a ello, la referencia al cartel nos permite ubicar temporalmente la acción de la novela. El afiche indica la celebración del décimo cuarto aniversario de la revolución rusa, la cual estalló en 1917; por ende, el cartel nos permite deducir que la acción de la novela se ubica después de 1931. 
cuando acaba de morir Bandera, la criatura producto de la relación que Julia mantiene con Fidel, cabecilla y acérrimo comunista que tiene a su cargo labores cardinales en pro de la causa.

En medio de tan macabra escena Julia apenas muestra pesar ante el fallecimiento de la niña, sin mayores visos de lamentación se interesa más en las palabras de Fidel que en llorar a su pequeña. Esto refleja que Julia vive desposeída de sí misma y de sus propias emociones, todo por experimentar una dependencia absoluta del ser y el quehacer de Fidel. Esto podríamos conceptualizarlo como una enajenación, pues Julia le ha transmitido a él, el domino o el derecho de su propia vida. Semejante afirmación nos lleva a decir que Julia ha retorcido su existencia, deformando por completo el control de su ser y de sus sentimientos. De hecho, la misma Julia acepta que su reacción sería otra de no estar frente a Fidel: "Lo que hubiera querido decir. Las hondas y desgarradoras palabras. El llanto que hubiera querido derramar" (Revueltas, 1979: 64).

Mientras Julia, Fidel y los militantes Bautista, Ciudad Juárez y Rosendo son mudos testigos de la tragedia de la pequeña Bandera, Fidel aprovecha la penosa situación para, en palabras de Julia: llevar a cabo una "artimańa de voraz proselitismo" (Revueltas, 1979: 67). Ello comienza cuando el joven Rosendo no puede soportar tan lamentable situación y decide fijar su mirada en una de las paredes del aciago refugio; tratando de distraer su mirada evita observar a Julia o a la propia Bandera. Entonces su vista encuentra un cartelón propagandístico de la revolución rusa en el que un obrero con el rostro encendido ondea su bandera revolucionaria. ${ }^{12}$

${ }^{12}$ Es significativo que el propio Revueltas insista en la supremacía del simbolismo histórico del afiche y no tanto en la mediocre imagen; por eso quizá decidió no valerse de un objeto visual existente fuera del texto. Así apuntaba a que en estos elementos propagandísticos es más importante la significación que la recreación tangible. Algo similar sucede con el cuadro de Braque que revisaremos posteriormente, en él, la estética del movimiento cubista per se resulta ser más valiosa que la descripción exhaustiva de una imagen precisa. 
Debido a la triste realidad que presencia, Rosendo no encuentra motivante el afiche y lo pasa de largo para seguir inmerso en la pena y prácticamente llegar hasta las lágrimas. De todo eso se da cuenta Fidel, quien utiliza un tono proselitista para enarbolar la lucha incansable sin lamentaciones o distracciones emocionales (como enterrar a su propia hija). Es así como Fidel logra obtener la admiración de Rosendo, para quien simbólica y literalmente la causa política cobra fuerza, entiende entonces que la esperanza de la Revolución sigue viva y la muerte de Bandera es sólo un sacrificio en el camino para consolidarla.

Fidel logra que el cartelón soviético adquiera sentido ante Rosendo y Julia pero de maneras muy diferentes: mientras para el joven militante el afiche es símbolo de exaltación, para Julia aquella imagen llena de bríos es el comienzo del fin de su relación con Fidel. Julia atestigua la escena proselitista detonada por el cartel y hasta ese momento toma conciencia de la deformación de su pareja, quien "es como un abominable santo [...] un santo capaz de cometer los más atroces pecados de santidad" (Revueltas, 1979: 71). La escena en la que se recurre a la ecfrasis del afiche despliega la reflexión de Julia, ésta comprende el sacrificio de querer a un hombre así, con una idea tan perversa del amor, con una cosmovisión repleta de distorsiones. Pero a pesar de captar la perversión de Fidel, Julia no se percata de su propia distorsión; de hecho, emocional y psicológicamente es ella quien más perturba la noción de humanidad, sobre todo porque pervierte una condición tan paradigmática como la maternidad. Julia se muestra como una madre cómplice de la muerte de su hija, distorsionando la típica imagen materna porque contraría el sentir de una mujer que acaba de ver morir a su bebé.

La perversión de Julia es tal, que enajenada por las ideas de Fidel ha permitido la muerte de Bandera por inanición. Incapaz de hacer algo que ponga en riesgo a los militantes, Julia no toma 
ninguna acción para evitar que Bandera muera de hambre. ${ }^{13}$ Julia se ha dejado arrastrar por Fidel y sus formas distorsionadas de percibir la vida, las cuales refleja en momentos cruciales, como cuando pone en segundo plano el fallecimiento de la nińa y entiende su deceso como un sacrificio por la causa. Y es que Fidel sólo muestra interés en la entrega de la propaganda política, con ello busca demostrar que hay cosas más trascendentales que la descomposición del cadáver de su hija. Al hecho de la muerte y a sus efectos emocionales "no se le debería conceder la menor importancia cuando la vida estaba tan llena de cosas que eran mucho más serias y trascendentales" (Revueltas, 1979: 61).

Aunado a estas distorsiones psicológicas se ańade una de tipo emocional: Julia no soporta tocar el cuerpo de su hija y retira sus manos con disgusto en cuanto entra en contacto con ella, es más, ni siquiera ha sido capaz de llorarla. Julia ha mermado su más elemental humanidad incluso hasta el punto de verse comparada con algo cuasi inerte. Este personaje parece confundirse con un árbol yerto y espinoso, como se explicita en las siguientes líneas: "Ahí en el rincón [de la oficina clandestina] era igual a esos tristes huizaches, que sin hojas, sin vestiduras, se nutren con quien sabe qué de lo más pobre y último que les puede dar una tierra bárbara y estéril” (Revueltas, 1979: 64). Así se exhibe a Julia como una mujer carente de sentimientos maternos quien, prácticamente seca por dentro no es capaz de amar —o quizá es mejor decir, no es capaz de expresar su amor- a la sangre de su sangre. Dicha comparación de Julia con un yerto huizache se pondera aquí como el punto climático de la distorsión emocional del personaje protagónico femenino de Los dias terrenales.

${ }^{13}$ Resignada y melancólica se limita a contemplar la agonía de la niña "tiene dos días de no poder cerrar los ojitos" (Revueltas, 1979: 68), peor aún, sabedora del fatal desenlace, se atreve a confesar "vale más que acabe cuanto antes" (Revueltas, 1979: 68). 
Pese a ser, como hemos dicho, un pilar en la historia, Julia está lejos de tomar plena conciencia de su importancia en el contexto que la rodea, incapaz de tomar decisiones e inhabilitada en la causa política ante el peso específico de Fidel, Julia simplemente se deja llevar. Mientras manipulada e inconstante observa la paulatina putrefacción de la niña, su mente sigue inmersa en el devenir de la causa; precisamente debido a ello repara en que la utilización del cartel ruso es una hábil táctica y un símbolo del intenso dogmatismo y capacidad de dirigencia de su pareja... por eso, yerma y fría (tal cual el espinoso árbol), Julia le concede a aquel líder el derecho a decidir que el entierro de la pequeńa Bandera pueda esperar ante la importancia de la causa y sus asuntos urgentes e inaplazables.

Los antecedentes desarrollados hasta aquí acerca de la relación entre Julia y Fidel, permiten reconocer que el liderazgo de Fidel va de la mano de una intensa capacidad de trastocar los ideales e incluso el sentido común de quien lo rodea (como la propia Julia), sin embargo, una última vinculación ecfrasis-personaje consentirá reafirmar la exposición de la existencia deformada del cabecilla comunista; ello a partir de la reflexión y la actitud que toma cuando se topa con el cuadro del artista cubista francés Georges Braque.

\section{Fidel y pintura de Braque}

Desempeñando sus funciones jerárquicas dentro de la causa, Fidel visita la casa de un simpatizante del movimiento. En su afán de cumplir a carta cabal llega con anticipación a la cita y debe esperar en el estudio el arribo de los compańeros; mientras aguarda observa la habitación y se molesta por el lujo y la comodidad ostentosa de aquellos que intentan ayudar económicamente en la militancia; en su recorrido visual de pronto nota algo que llama su atención, Fidel contempla un pequeño cuadro que de inmediato le produce: 
Una inconcebible reacción, desdeñosa y colérica, pero llena de interés. Debía tratarse de una de esas cosas modernistas o surrealistas, quién sabe. Una combinación incomprensible de figuras geométricas, triángulos, trapecios, rombos, cilindros, interfiriéndose unos con otros, descompuestos sus volúmenes por la incidencia de líneas diagonales y horizontales que iban de aquí para allá, de uno a otro lado (Revueltas, 1979: 181-182).

Fidel entiende esa expresión pictórica como una deformación generalizada y concibe ese tipo de arte como perverso. No puede, o mejor dicho, no quiere entender esa manifestación visual porque según él, se trata de una expresión criminal que en nada contribuye a la formación del hombre político. Para Fidel la obra es "un arte incomprensible para las masas" (Revueltas, 1979: 183) ya que se basa únicamente en el empleo y predominio de formas desorganizadas, descompuestas y superpuestas. ${ }^{14}$ Fidel muestra su intolerancia ante todo aquello que no participa de sus rígidos ideales políticos y sus concepciones geométricas de vida; ${ }^{15}$ de ahí que el cuadro lo haga sentir "un desprecio singular en que, sobre todo, había la conciencia profunda, conmovedora, sorprendente de sentirse superior, muy por encima de esas formas de mirar la vida" (Revueltas, 1979: 182; cursivas mías).

Fidel desprecia dichas formas pues no encuentra en ellas el claro compromiso social que para él debería tener toda manifestación artística. El cuadro representa sólo manchas, trazos, formas, sim-

${ }^{14}$ Ciertamente Georges Braque apela por una escisión con la pintura tradicional pues es uno de los mayores exponentes del cubismo, vanguardia que no atiende a la imitación material y rompe con la perspectiva, el punto de vista único, etcétera.

${ }^{15}$ Entrevistado por Norma Castro en 1967, José Revueltas afirma que "Fidel representa el prototipo del dogmático para quien el marxismo es una religión, precisamente, y no un método de conocimiento. Fidel es un fanático, un cura rojo" (Castro, 2001: 40). 
ples figuras en donde es imposible ver una vinculación ideológica con el comunismo, por eso se pregunta el porqué de algo tan infecundo y carente de sentido, "Aquello le pareció horrible... e inmoral. Un símbolo donde se resumía toda la decadencia burguesa” (Revueltas, 1979: 182). Dicha decadencia burguesa y ese tipo de manifestaciones artísticas vanguardistas no tienen cabida en una mentalidad tan cerrada como la de Fidel, quien es uno de esos hombres que "no podían razonar sino dentro de la aritmética atroz que aplicaban a la vida. [...] La aritmética de la vida. Dos y dos son cuatro, dos y dos son cuatro, dos y dos son cuatro. Sobre todo Fidel. Sobre todo el pobre de Fidel” (Revueltas, 1979: 92).

En pocas palabras, Fidel posee un evidente espíritu geométrico (es decir, exacto, rígido, preciso) que "deriva de su manera de asumir el comunismo, en forma doctrinaria [...] Él se forja con este sistema de ideas un cerco mental que acaba por confinarlo y lo deteriora como ser humano" (Negrín, 1995: 191). No obstante su exasperante forma de vida preceptiva y altamente cuadrada, Fidel es incapaz de notar que sus preformaciones y prejuicios mentales lo han llevado a deformar por completo su vida y sus relaciones personales.

Ya habíamos señalado los entreveros de una de esas relaciones disfuncionales, en específico la que Fidel mantiene con Julia; por ejemplo, cuando acaba de morir su hija quiere expresar su amor por su pareja, mostrarse como un padre entristecido, acompañar el dolor de Julia con palabras sensibles y salidas del corazón, no obstante, inmediatamente cambia de opinión y transforma su discurso en un pronunciamiento político, todo porque su proceder siempre rígido antepone su papel de líder inflexible al de hombre superado por la desastrosa realidad.

Es esa rígida realidad contextual la que le impide acceder a otras perspectivas y a otros planteamientos conceptuales, por eso su desdén a expresiones artísticas como las de Braque. Aunque en 
apariencia desaprueba tal pintura, al verse solo ante ella se atreve a deleitarse contemplándola y encuentra en ello la vibrante sensación de hacer algo prohibido: "Lo examinó con un cinismo desenfadado y total. Mirar aquello era la consumación de un delito del que nadie se enteraría jamás. Rombos, rectángulos, pirámides, cilindros, cubos. Líneas de color malva, blancos incandescentes, algunos fondos rosa y en el ángulo superior derecho un destello, una mancha verde agresiva” (Revueltas, 1979: 182). La idea de estar cometiendo un crimen al ver el cuadro sólo acentúa su re-torcido comportamiento, y es que su errada idea de ser un hombre comprometido lo ha llevado a cometer verdaderos crímenes humanos (como la absoluta displicencia y casi consentimiento en la muerte de su hija). Sin embargo, Fidel no se da cuenta de sus verdaderos errores porque en su actuar él sólo ve el proceder adecuado de un comunista que no tiene tiempo para lamentarse.

Enajenado por la militancia política Fidel tuerce o desequilibra el comportamiento racional. Sus actos responden sólo a un dogmatismo trascendental y por consiguiente, su compromiso con la causa raya en lo insensato, su forma de mirar la vida está plagada de distorsiones. Hay en él una profunda perversión emocional y espiritual que se nota en su deshumanización y en "su absurdo celo a la doctrina como una forma de evitar el enfrentamiento con sus emociones" (González, 2001: 37), por ende, completamente entregado al partido: desdeña el amor de Julia, no se permite lamentarse por la muerte de su propia hija y deja atrás al sano juicio con sus posturas ideológicas retorcidas.

Con este comportamiento Fidel nos hace comprobar su intensa perversidad, sin embargo, él únicamente se enfoca en señalar y combatir la distorsión ajena (como la intencionada deformación artística y estilística de la pintura de Braque, la fragilidad evidente de Rosendo o la militancia controversial de Gregorio) y no admite sus propios equívocos y desviaciones. Estar ante un cuadro cubista 
que podría considerarse como una clara expresión de la deformación radical (según las normas miméticas del arte) bien podría servir como el reflejo de las propias distorsiones de Fidel, pero él no lo ve así. Ciego como está, arrastra a la oscuridad a todo aquél que lo acompaña en su camino.

Así las cosas, concluimos que la ecfrasis de la obra de Braque se convierte en un valioso recurso de la novela para exhibir la enorme contradicción del protagonista, ya que a pesar de su distorsión interna no da cabida en su cosmovisión a otras expresiones "deformadas" como la representada por la pintura vanguardista. La vinculación de Fidel con este objeto artístico lleva al lector a reflexionar con respecto a que esa pintura no es sólo un detonante para la crítica del líder comunista respecto al arte, la obra pictórica además es un indicativo que refuerza la distorsión interna de Fidel, personaje que incluso es denominado en el propio texto como "un esquema, un fenómeno de deformación, de esquematismo espiritual" (Revueltas, 1979: 175)... la joya de la corona en cuanto a distorsión se refiere. Por tanto, esquematizado y rígido, Fidel no da cabida en su vida a nada que desdibuje la geometría exacta y perfecta que ha establecido como preceptiva existencial

\section{Consideraciones finales}

En definitiva, la lectura ecfrástica de Los dias terrenales es una opción para ver implicaciones externas dentro de una lectura productiva que no se limita a los lindes y espacialidades textuales. Así las cosas, la respuesta a la problematización que planteábamos en las primeras páginas es positiva, efectivamente los tres diferentes recursos ecfrásticos en el texto, uno de tipo referencial (El entierro del conde de Orgaz) y dos referenciales genéricos (la pintura de Georges Braque y el cartelón de la revolución rusa) subrayan la distorsión generalizada de los personajes centrales. 
Es a partir de esta vinculación ecfrasis-protagonistas que nuestra lectura se vuelve significativa y aporta algo más a los múltiples análisis de la novela; sobre todo debido a que gracias a los recursos ecfrásticos se resalta que en su particular enajenación, Gregorio, Julia y Fidel deforman su carácter y distorsionan la realidad, pero mientras perciben la perversión del entorno, del otro o de los espacios otros, no interiorizan el problema y descubren sus notorias perversiones.

En síntesis, las ecfrasis orientan un anclaje para la lectura homogénea del texto pues como vimos, poseen una gran densidad simbólica que los hace sentar vínculos directos con los protagonistas. Con este trabajo pugnamos por explotar los sentidos potenciales de la novela de Revueltas, la cadena de relaciones con otros espacios siempre es interesante y en este caso, pensar en las referencias ecfrásticas como simple ornato de la narración podría llevar a perder múltiples sentidos presentes en Los días terrenales. Esto último no significa que la interpretación de la perversión de los personajes esté en riesgo de perderse si se desdeñan las ecfrasis, pero también es cierto que la ecfrasis contribuye y complementa las semantizaciones de la obra, ante todo porque las expansiones o predicaciones de los tres diferentes objetos plásticos conforman un eje generador de sentido que enfatiza que: "la mirada del narrador Revueltas, siempre [está] centrada en la negatividad: lo caótico, lo sórdido, lo oscuro, lo perverso" (Negrín, 1995: 179; cursivas mías).

Para hacer un apuntamiento final debemos recordar que el espacio ya de por sí significativo del objeto artístico extratextual o autorreferencial se re-significa en una lectura ecfrástica de Los dias terrenales, ello permite que el lector haga un redescubrimiento de la obra plástica. Pero sobre todo facilita develar que en el texto narrativo esos espacios otros pueden fungir ya sea como una especie de síntesis entre espacio y personajes (donde uno refleja la deformación del otro); o como un apuntalamiento de la distorsión 
y perversión característicos en la obra, sugiriendo así, el ya célebre "lado moridor", aspecto agónico y dolorido de la narrativa de José Revueltas.

\section{Bibliografía}

Castro Quiteño, Norma, 2001, "Oponer el ahora y aquí de la vida, el ahora y aquí de la muerte" en Conversaciones con José Revueltas, Andrea Revueltas y Philippe Cheron (comp., pról., notas e índice), México, Era, pp. 36-42.

Cuevas Velasco, Norma Angélica, 2006, El espacio poético en la narrativa. De los aportes de Mauricio Blanchot a la teoría literaria y de algunas afinidades con la escritura de Salvador Elizondo, México, UAM.

Diccionario de la Real Academia Española, 2001, 22a ed., versión electrónica, disponible en: http://buscon.rae.es/draeI/ (consultado en II/2013)

Escalante, Evodio, 1999, "Los laberintos de la dialéctica en las novelas de Revueltas" en Nocturno en que todo se oye. José Revueltas ante la crítica, Edith Negrín (sel.), México, Era / UNAM, pp. 128-137.

1991, "Circunstancia y génesis de los días terrenales" en José Revueltas, Los días terrenales, edición crítica, México, Conaculta, pp. 191-214.

González Torres, Armando, 2001, “José Revueltas. La lucidez y el desamparo" Viceversa, núm. 95, abril, México, Gatuperio, pp. 34-39.

Krieger, Murray, 2000, "El problema de la ecfrasis: imágenes y palabras" en Literatura y pintura, Antonio Monegal (comp.), Madrid, Arco/Libros, pp. 139-160. 
Mesa Sanz, Juan Francisco, 2010, "Rethorum itinera: ecfrasis" Eikasia. Revista de Filosofía, núm. 32, año V, mayo, Oviedo, pp. 173-196.

Mitchell, W. J. T., 1994, "Ekphrasis and the other" en Picture Theory, Chicago, University of Chicago, pp. 151-181.

Negrín, Edith, 1995, Entre la paradoja y la dialéctica. Una lectura de la narrativa de José Revueltas, México, UNAM / El Colegio de México.

Paz, Octavio, 1983, “Cristianismo y revolución: José Revueltas” en Hombres en su siglo, Barcelona, Seix Barral, pp. 141-155.

Pimentel, Luz Aurora, 2001, El espacio en la ficción, México, Siglo XXI.

, 2003, "Ecfrasis y lecturas iconotextuales" Poligrafías. Revista de Literatura Comparada, núm. IV, División de Estudios de Posgrado, Facultad de Filosofía y Letras, UNAM, pp. 205-215.

Revueltas, José, 1979, Los días terrenales, México, Era.

Revueltas, Andrea, 1999, "José Revueltas: política y literatura” en Nocturno en que todo se oye. José Revueltas ante la critica, Edith Negrín (sel.), México, Era / UNAM, pp. 51-60.

Riffaterre, Michael, 2000, "La ilusión de ecfrasis" en Literatura y pintura, Antonio Monegal (comp.), Madrid, Arco/Libros, pp. 161-186. 